\title{
THE DEVELOPMENT OF THE CONCEPT OF HYPOXIA-ANOXIA ${ }^{1,2}$
}

\author{
Cyril B. Courvillee; M.D. ${ }^{3}$
}

IT MATTERS LITTLE what field of medicine one wishes to explore from the viewpoint of history; the development of knowledge about it seems to follow a similar pattern. At first, only the most obvious features of a natural phenomenon are noted, such as would be apparent to the average lay mind. Then some simple deduction as to the significance of this phenomenon is made and verified until it becomes a part of current "knowledge. Other observations which emphasize different features of the concept are then slowly added to this store of information until the crude outlines of the subject can be distinguished. After printing was invented, this process accelerated since general observations could be put under the scrutiny of many individuals. Experimentation finally subjects these concepts to critical test so that the fundamentals of scientific thought are finally worked out. This evolution of thought about any natural phenomenon is a very slow process, requiring thousands of years even for the rudiments of an idea to become well known.

The historical development of knowledge of the significance of respiration in its relation to the effects of oxygen-want on the nervous system follows this pattern, as will be briefly outlined herein.

Prehistoric man undoubtedly experienced difficulty in breathing when exposed to the smoke of his cave campfires; certainly he occasionally suffered from laryngeal obstruction from a hastily gulped bolus of meat, or nearly drowned in the lakes whose borders he dared trespass. However, if he had any ideas about the absolute necessity of respiration to life, we have no way of knowing it. Hence, any attempt to trace, from the beginnings of things to the present, the concept of impaired respiration in its broadest sense, is to undertake the impossible. The writer will be forgiven, he hopes, if this historical approach to the human conception of oxygen-want proves to be rather sketchy. Yet it may be profitable to trace its tenuous course throughout a period of four thousand years or more.

\section{Anoxia in Ancient Times}

There is direct evidence that prehistoric man occasionally suffered from the effects of oxygen-want to the point of his individual extinction. This is suggested

'Presented at the meeting of the Western Divisions, Canadiar. Anaesthetists' Society, at Victoria, B.C., April 28-30, 1960.

2In order to avoid confusion, the terms hypoxia and anoxia are used in the sense suggested by Wiggers (1). Accordingly, hypoxia implies a lowered oxygen tension in the blood with evddent physiological changes which are reversible leading to complete normalcy; anoxia indicates a state of oxygen lack to a degree resulting in pathological alterations in the brain resulting in fatal issue or physical and/or mental deficits during the survival period.

"From the Division of Nervous Diseases (Neurology), College of Medical Evangelists, and the" Cajal Laboratory of Neuropathology, Los Angeles County Hospital, Los Angeles, Califf. 
by the discovery of a skeleton found buried in the shaft of a flint mine at Obourg, Belgium. Three other skeletons were discovered under a landslide at La Ferrassie, France. All these individuals had evidently been suffocated by being suddenly covered with earth. Less dramatic were the effects of respiratory embarrassment from breathing of rarefied atmosphere. Aristotle (384-322 в.с.) probably referred to a common experience when he complained that the air on Mount Olympus was too thin for respiration. More significant are the stories of drowning in ancient times in which many individuals came to their end. According to Pliny and Celsus, drowning was considered to be a form of suffocation, a concept which was widely accepted throughout the Middle Ages and Renaissance (for example, Sylvius, 1635). A study on the cause of death in drowning was instituted by Nachtigal (1775-6), bringing this problem well up to recent times.

Mechanical strangulation, both accidental and purposeful, has also been known from ancient times, being used by the Assyrians and the Babylonians either for capital punishment or for the destruction of prisoners of war. While this mode of exitus was recognized in Biblical times as a horrible way to die (Job 7:15), it is not known what was thought to be the mechanism of the victim's death. That this form of asphyxia was recognized as an interference with respiration was suggested by the methods of execution used by the Chinese of the late dynastic period. The upper air passages of the victims were plugged solid with wads of paper soaked in spirits. This is also indicated by the common practice of infanticide in the Middle Ages when mothers rid themselves of unwanted infants by pressing their mouths against the mattress of their cribs.

\section{Anoxia and Foreign Gases}

Thus the stage was set for the idea that air was a necessity of life and that a sufficient amount of it must have access to the lungs at all times. If the air was "too thin" or if there was any mechanical obstruction to its entrance to the lungs, severe distress occurred which was sometimes followed by death. This was perhaps the first accepted concept with respect to hypoxia. The second important concept seemed to follow naturally, that is, when any vapour or gas replaced the air, symptoms similar to suffocation would occur.

Somewhat akin to our present understanding of the relation of nitrous oxide to anoxia was the observation of asphyxiation incident to certain noxious gases. This was presumably a common cause of death among the slave miners of Egypt and laborers in the silver-lead mines of Greece. It is difficult to be certain, however, that the Greeks were actually aware of the precise cause of death in these cases. The fact that fires were kept burning in the tunnels and shafts of these mines suggests the suspicion that stagnation of air was indeed responsible. The first indication that this situation was correctly understood was a statement of Vitruvius (first century A.D.) to the effect that death in the mines could follow inhalation of noxious vapours. He advocated that a lighted lamp be introduced in to the shaft before the miner descended into it. If the light continued to burn, the shaft was considered safe. Whether conternporary mediaeval physicians went a step further and recognized the necessity of some normal constituent of air in 
order to prevent such catastrophies is uncertain. It is safe to say, however, that Galen (A.D. 131-201) 'was the first physician to call attention to the suffocating effect of extraneous fumes in the copper mines of Cyprus. This appreciation probably marks the earliest concept of asphyxiation by a replacement of normal constituents of air by some other gaseous substance. Such a conclusion was supported centuries later by the observations of Agricola (1556), a mining engineer, who observed that the presence of such gases was the cause of 'difficulty of respiration, a symptom which sometimes resulted in actual suffocation. In the eighteenth and nineteenth centuries, it was recognized that these noxious gases constituted a foreign element in the air and that they occurred most abundantly in coal mines.

Early in the Christian era, it was reported that accidents sometimes followed inhalation of fumes from burning charcoal. Erasistratus (ća. 300 B.c.) had suspected even at this early date that the vapours issuing from the heated charcoal somehow diluted the air with consequent deleterious effects. Avicenna (ca. A.D. 1000), anticipating Larrey by over 800 years, went so far as to consider this vapour a "brain poison." Christophe a Vega (1576) expressed the belief that serious symptoms, even death, could follow the inhalation of this gas. While the more superstitious were inclined to believe that death under these circumstances was the work of the devil, others were equally convinced that this was not true. This second group offered as evidende to the contrary the fact that Pope Clement VII met his death in this manner. He succumbed from breathing the fumes from burning torches carried before him in a religious parade. The first experimental evidence of this suffocating effect of fumes was offered by Boerhaave (1732), who demonstrated that an animal would quickly succumb to the vapour given off by burning organic matter. ${ }^{4}$ An accidental experiment in human beings was described by Larrey (1814), the great military surgeon serving with Napoleon's armies. He noted in the case of a group of soldiers who slept in a closed chamber heated by a stove, that those who slept nearest the windows escaped, while those who slept nearest the stove succumbed. But most important of all was Larrey's conclusion, which agreed with that of his contemporaries Portal and Bichat. He concluded that "the brain and the nervous system which arrises from it are almost suddenly paralyzed by the rapid transmission and diffusion of the deleterious carbonick principle, that is in the first place absorbed by the lungs and carried to the brain with the arterial blood. ..."

\section{Anoxia and the Development of Anaesthesia ${ }^{5}$}

Coincident with this development of the idea that certain types of gases could replace the oxygen in the air with disturbing if not disastrous effects, some similar

${ }^{4} \mathrm{~A}$ review of the articles appearing on this subject in the eighteenth and the first part of the nineteenth centuries indicated that it was not only carbon monoxide that could "supplant the oxygen in the air to produce asphyxia. The surcharging of inspired air with carbon dioxide resulting from fermentation, or even the presence of gases from decaying organic matter was also able to do this.

${ }^{\mathrm{A} A}$ more complete history of cerebral anoxia with its relation to anaesthesia can be found in the writer's monograph on this subject (2). 
qualities of the gas now known as nitrous oxide were observed by Priestly (1774). Because of hilarious behaviour of individuals inhaling this vapour, it was called "laughing gas." This property was therefore utilized to produce a narcotic effect similar to alcohol. It was soon suspected that the convulsive seizures sometimes associated with its use were due to the accompanying anoxaemia and were not apt to occur if a sufficient amount of oxygen was used along with it. Even though it was observed that injuries occurring while under the influence of nitrous oxide were not attended by pain, the idea of its being used as an anaesthetic agent was not quickly appreciated. It was Sir Humphrey Davy who, while experimenting on himself with this gas, found that the pain of an erupting wisdom tooth was considerably alleviated. He therefore recommended it (1800) in surgical procedures as a means of destroying pain. The peculiar effects of nitrous oxide, now recognized to be anoxic in origin, would require another century and more to be fully evaluated.

With the continued use of nitrous oxide as an anaesthetic, certain features of its nature became increasingly apparent. It seemed certain that there existéd a degree of inherent narcotic action of this gas as compared with an inert gas such as nitrogen. On the other hand, a considerable degree of anoxaemia was also present in deep surgical anaesthesia. Moreover, this anoxaemia seemed to reinforce the anaesthetic action of the gas. This was shown in the untoward effects of nitrous oxide as manifested by the complicating symptoms which were strongly reminiscent of anoxia. This curious admixture of the narcotic and anoxic effects of nitrous oxide left its status confused. ${ }^{6}$ This was especially true with respect to the symptomatology which preceded death in fatal cases. Here matters stood until the early 1930's.

\section{Cerebral Anoxia and Nitrous Oxide}

It was at this point that the writer entered the picture purely by chance. $\mathrm{He}$ was then in charge of the Neuropathology Laboratory of a large general hospital. As a result of serious complications of nitrous oxide anaesthesia, nine patients died within a short interval of time, while another survived with severe crippling residuals. A careful study of the brain in the fatal cases disclosed a fairly typical pattern of progressive changes in the cerebral gray matter in the form of patchy and laminar necrosis. This alteration was most marked in the motor and visual cortex, less so in the parietal and frontal areas. Necrotic changes in the globus pallidus, so characteristic of fatal cases of carbon monoxide "poisoning," were also present. These alterations first became evident in the brain of a patient who survived for 37 hours. They became progressively more marked as the survival

${ }^{6}$ In what is probably the first comprehensive treatise on the physiology of anaesthesia, Claude Bernard (3) raised the question whether anaesthesia was after all simply a form of asphyxia because both produced unconsciousness. Thus the physiological state of narcosis which is now referred to as anaesthesia, and "asphyxia" as its most serious complication were simultaneously evaluated. We cannot now tell how Bernard would have dealt with the complex problems relating to the chemistry and physiology of nitrous oxide which presented themselves in the next halfcentury. But his answer, and the reason therefore, were quite simple. No, anaesthesia was not asphyxia, for in anaesthesia the arterial blood retained its normal colour and oxygen content. 
period stretched into days and weeks. These periods were so varied as to permit the elaboration of a fairly complete chronological picture of the entire process. When the results of this study were submitted by the writer to ${ }_{i} \mathrm{Dr}$. Yandell Henderson for his opinion, he promptly recognized that brain damage in these cases was unquestionably due to the occurrence of anoxaemia.

There has been much discussion as to the precise role of anoxaemia in the administration of nitrous oxide anaesthesia. Some astute anaesthetists on both sides of the Atlantic insisted that it was not the nitrous oxide gas that was at fault, but rather the way in which it was administered. The present writer, who makes no pretence of having any technical experience in anaesthesia, could only reply, "Whereas these unfortunate individuals were once alive, they are now dead. They experienced clinically what seemed to be an anoxaemic episode under nitrous oxide anaesthesia, and after death, their brains are stamped with unequivocal signs of an anoxic process." It was up to the academicians in the newly developing specialty of anaesthesia to debate the question of the precise mechanism of the obvious cerebral anoxia. ${ }^{7}$

The different viewpoints of the "schoolmen" on the subject of nitrous oxide were variously expressed. Some were a little piqued that a rank "outsider" would dare to speak thus against their favourite anaesthetic agent. Others welcomed the study as a disclosure of the real dangers in its use. At any rate, several very practical results followed this pronouncement. Soon a purer type of nitrous oxide was produced by the manufacturers, more accurate machines were developed to administer it, and improved methods with the use of larger percentages of oxygen were forthcoming. Viewed from this angle, the disclosure of the dangers of nitrous oxide was well worthwhile. 'At least, it served as a warning to the novices who had used the gas without due attention to the risks involved.

The studies of individuals other than the author, dealing with the untoward effect of nitrous oxide $(5,6,7)$ established beyond question the fact that this agent was capable of producing profound, irreversible, and at times lethal effects of anoxia if not carefully used. In many instances,| the warning signs of defective oxygenation of the brain (hypoxia) were quickly tecognized and the tide turned in the direction of recovery. Experience with this agent in the past two decades and more has proven that, when properly handled, nitrous oxide could still serve as a useful agent although in the writer's experience, accidents still occurred. These accidents seem to complicate nitrous oxide anaesthesia more often when combined with large doses of pre-anaesthetic drugs and/or other anaesthetic agents.

Hypoxia and anoxia were not alone the results of nitrous oxide anaesthesia. In the same period in which this agent was being investigated, a number of cases

${ }^{7}$ And this is precisely what happened. The publication of a monograph on this subject (4) some three years after publication of the first somewhat extended report was followed by an exacerbation of a latent argument among the anaesthetists of England. These divided themselves into protagonists and antagonists on the subject of nitrous oxide anaesthesia, using the pages of the famous Lancet of London as their sounding board. The monograph was used with some apparent success by the "antis" against the "pros," but with the author always in the crossfire of the feud. 
with fatal outcorme from other inhalation anaesthetic agents came to light. Cyclopropane, for example, was found to produce fatal effects of oxygen-want (8). The point to be made in this connection is that most general anaesthetic agents can produce brain damage by this means. ${ }^{8}$ This brings to mind the statement of Beecher and Todd (10) to the effect that hypoxia-anoxia is still the greatest enemy of the anaesthetist.

\section{Contributions of Anaesthesia to the Curkient Concept of Hypoxia-Anoxia}

This brief review of interest in anoxia over the past quarter-century makes it clear that one fof the most important aspects of this subject lies in its connection with anaesthelsia. Moreover, since this renewed interest in cerebral anoxia came about through the effects of one of the popular anaesthetic agents, that is, nitrous oxide, it is worthwhile to note the contributions to this subject that have been made in the past quarter-century. At this point, the present writer is obliged to speak largely from his own experience, drawing conclusions from both his clinical and his pathological observations. It is recognized, of course, that drawing lessons from pathology is none too popular today. Animal experimentation seems rather to be the method of choice. Were it not for the fact that animals do not always react like human beings from the viewpoint of objective behaviour, and that their brains do not present the same residuals from experimentally induced anoxia, observations on the human "animal" would likely be discarded entirely. Nevertheless, some lessons have been learned which seem to be of primary interest to those who carry on their minds and hearts the responsibility for the wellbeing of their patients.

It is well to point out these specific lessons and then to deal with them one by one.

(1) All anaesthetic agents are body poisons, always inherently dangerous and sometimes lethal, if not properly used.

(2) These agents act on the body tissues chiefly through"their narcotic actions in so far as their normal behaviour is concerned. Because the grey matter of the brain (that is, the portion which contains the nerve cells) is most vulnerable to the effects of oxygen-want as well as narcosis, it is in this portion of the nervous system that structural changes are first to appear.

(3) The narcotic effect of anaesthetic agents seems to be a double one, the

${ }^{8}$ It is well known, of course, that the primary noxious effect of chloroform is on the liver; no cases known to the present writer bear out the idea that cerebral hypoxia occurs under its influence. As for ethyl ether, the problem is not entirely clear (9). In the very few cases, studied by the writer, evidence seems to imply that there is a noxious effect on the cerebral gray matter, but the pattern of change is not typical of anoxia. The cerebral gray matter, especially the cortex, appears to become brittle and to undergo a peculiar fissuring and fragmentation, and in some instances at least, this change is particularly marked about the blood vessels. The writer has chosen to leave the matter of the noxious effects of ether on the brain as an unsolved problem for the present. 
primary effect aș such acting directly on the cortical nerve cells, while another secondary effect serves to depress the vital centres, particularly the vasomotor centre.

(4) While the desired narcotic effect of an andesthetic agent is its tendency to depress the nerve cells of the cerebral cortex, an associated anoxic effect is achieved through an impairment of the vital centres, disturbing respiration and circulation. Alteration in vasomotor functions tends to result in ischaemia, with localized alterations in the brain tissues.

(5) Clinical evidence seems to indicate that an accumulative effect on the respiratory, cardiac, and vasomotor centres is exerted by multiple pre-anaesthetic sedatives and anaesthetic agents used in conjunction therewith. Each drug acting in its own specific way, not infrequently tends to depress these centres unduly and to lead to their functional failure.

(6) The precipitation of an acute failure of the vital centres in the course of an anaesthesia is usually due to the combined effect of the anaesthetic agent or agents and any pre-existent factors which per se predispose to hypoxia.

(7) The best prevention of anaesthetic hypoxia-anoxia must lie in the personal qualifications of the anaesthetist-such as a knowledge of pre-anaesthetic status of the patient regarding his inherent potentials favouring the development of the anoxic state, his experience with the behaviour of the proposed anaesthetic agent, and constant attention to the status of the patient under the anaesthetic.

A brief elaboration of these individual observations will make clear certain fundamental aspects of the hypoxic-anoxic state as held currently by the present writer.

\section{Anaesthetics as Brain Poisons}

When anaesthetists in Great Britain were laying the foundations of their professional organization, Dr. Lucas suggested that the society adopt as its crest that of the Borgias, who were so expert in the matter of administering poisons. If the writer is not misinformed, this step was actually decided upon. The prime purpose of this crest was to keep the membership constantly reminded that the agents which they used were indeed poisons, but ones which could be skilfully adapted to the well-being of their patients. That these toxic substances could not only produce transitory ill-effects, but could also destroy the patient through excessive dosage or misapplication of technique should be thought of whenever an anaesthetic agent is being chosen.

\section{Narcotic versus Hypoxic Effects}

The desired anaesthetic effect is achieved through the narcotic action of the drug on the nerve cells of the brain. The cells in the sensory system (the thalamus and the sensory cortex) and the centre of consciousness in the upper brain stem constitute the specific targets for this effect. If this narcotic action is not pero se a form of anoxia (that is, histiotoxic anoxia, acting through an interference with cellular oxidation), it closely resembles this process in its ultimate effects. But, while this desired effect is being accomplished, a coincident but less conspicuous 
depressive effect on the vital centres is also taking place. If this effect becomes excessive, an untoward reaction of one or more of three centres may occur. There may be respiratory irregularities (respiratory centre), an impairment of the peripheral circulation with drop in blood pressure (vasomotor centre) may follow, or actual cardiac failure (cardiac centre) may occur. Such an episode is usually as unexpected as it is critical. The seriousness of this situation lies in the fact that it is precisely under such circumstances that cerebral hypoxia may be precipitated and under which, if not successfully dealt with, cerebral anoxia results with irreparable damage. The extent of this damage decides whether the patient will survive with certain degrees of intellectual deficit, or with the more disturbing widespread motor paralysis, or whether he will die either at once or after a variable interval.

\section{The Dr. Jekyll and Mr. Hyde Effects of Anaesthesia}

The boon of successful anaesthesia to the surgeon as well as to the surgical patient are beyond computation. But while the blessing of anaesthesia through narcosis of the cerebral nerve cells is being attained, a similar but much less evident depressive effect on the vital centres is also going on. Unfortunately, these effects may not be apparent until sudden failure of these centres takes place. A successful anaesthetic, therefore, is one in which perfect narcosis of the patient is achieved without any appreciable effect on the patient's vital functions. The possible failure of these functions through excessive depression and the resultant effects on the brain is indeed the "spectre which haunts every surgical amphitheatre." For this reason, it is impossible for the anaesthetist to pay too much attention to these functions, for any warning of disaster can come only by their abnormal responses.

\section{The Specific Evil of Vasomotor Dysfunction}

Only through long attention to the mechanism of brain damage has the present writer come to appreciate the great importance of vasomotor instability in the ultimate structural changes in cerebral anoxia. It is now known that cerebral damage incident to anoxia is not a diffuse affair, one which tends to affect the entire brain, rather one has to do with selective damage, for the nerve cells of certain cortical laminae are more vulnerable than others. Moreover, certain portions of the convolutions are first to undergo physical change. Finally, some areas of the cortex are more prone to suffer early and more profoundly. All these variations can best be explained by the intervention of some vascular factor. This conclusion also seems justified because areas of softening of the cerebral cortex and subcortex as well as specific patterns of architectural change occur which are undoubtedly the result of ischaemia. This is implied because only an occlusion or spasm of the local branches of the cortical arteries or arterioles can explain these results. It is, therefore, impossible to evaluate the total picture, either clinically or pathologically, without taking into consideration this secondary ischaemic change. Vasomotor instability per se not only produces cortical changes, but also prolongs and intensifies the alterations produced by anoxaemia incident to an impairment or failure of circulation. The only appropriate treatment that 
remains available to the anaesthetist facing a serious hypoxic state is an attempt to restore vasomotor stability. ${ }^{9}$

\section{Danger in the Multiplicity of Narcotic or Anaesthetic Agents}

The writer's clinical contacts with patients who have suffered from the serious effects of a post-anaesthetic anoxic state has suggested the frequency with which several pre-anaesthetic drugs have been used to achieve preliminary sedation, and the multiplicity of anaesthetic agents that have been utilized in producing the subsequent anaesthesia. This has occurred so often, in fact, as to constitute in his mind one of the essential causes of an anaesthetic hypoxic episode. One visualizes the concept that the vital centres are individually influenced in different ways by the pharmacological action of each drug or agent. The introduction of each additional agent seems to add to the sum total of depression of the responsible nerve cells. Finally, the margin of safety is so much reduced that normal regulation is no longer possible. Under this state, any further insult to these centres results in their cessation of function with consequent cardiorespiratory collapse. Every young anaesthetist should become conscious of this problem to the end that any complexity of additional drugs or agents should be administered with great caution.

\section{Importance of Pre-existent Factors Favouring Hypoxia-Anoxia'}

In a recent review of the verified cases of fatal post-anaesthetic anoxias (12), the predisposing factors which seemed to favour the precipitation of a hypoxicanoxic disorder in the course of an ańaesthetic were sought. This review suggested that so often in cases with serious or fatal results of anaesthetic anoxic states, evidence exists which suggests the presence of significant pre-existing factors. Among these factors are (i) racial and group predisposition, (ii) familial predisposition, (iii) pre-existing functional or organic nervous disorders, (iv) preexisting pulmonary or cardiac disease, (v) excessive or prolonged sedation, (vi) acute or chronic alcoholism or narcotic addiction, and (vii) preoperative or operative haemorrhage. These factors need no special consideration, for their possible role in the production of an acute anaesthetic hypoxic state is all too evident. The point which needs to be emphasized is that these possibilities should always be reviewed with the patient before any induction of anaesthesia. In the writer's series of cases, many of the patients might well have been alive today had this precaution been followed.

\section{The Anaesthetic Technician versus Medical Scientist}

An outsider can only admire the rapidity with which this specialty of anaesthesiology has come to the fore in the past quarter-century. Among the most important of its achievements has been the recognition of the need of adequate training and supervised experience in the use of the various anaesthetic agents

${ }^{9} \mathrm{This}$ can be accomplished in some instances by the use of procaine hydrochloride, $1 \mathrm{gm}$. to a litre of 5 per cent glucose, given intravenously two or three times a day, as long as there is any hope of restoring the patient to consciousness or as long as cerebral dysrhythmia (as determined by an electroencephalogram) persists (11). 
and the complex equipment with which they are administered. At the present time, there is little to be desired in this regard in so far as the larger hospitals and medical centres are concerned. But there remains still a large area in which anaesthesia is administered by poorly trained personnel. In these areas, anaesthetic accidents sull occur. To assume a pharisaical attitude that all is well with anaesthesia, that any reference to anaesthetic anoxia is now quite out of date, is not only foolish but neglectful to the point of being criminal. What is to be done about the general practitioner in a small community who steps in and gives an occasional anaesthetic for the local surgeon? Should there be an effort to make him aware of the technical intricacies of his problem and the nature of the "brain poisons" which he administers? It is true that time will solve this difficulty, when all anaesthetists are well trained, but what of the fatal cases that will occur in the meantime? Whether this situation calls for an interval programme of instruction for these "temporary anaesthetists" or whether such practitioners of the art should be limited to the use of the simpler agents with which they may become more easily acquainted, is a problem for groups such as yours. The lesson which our present concepts of anoxia teaches is that this complication usually comes from lack of knowledge of the agent and techniques of its use. Disabilities from anaesthetic accidents can be so permanent or even fatal that some efforts should be made to avert the tragedies which follow their occurrence. But the responsibility of your speaker, a "layman" in so far as anaesthesia is concerned, can be only to emphasize the dangers of cerebral anoxia and some of the ways in which it may be avoided.

\section{REFERENCES}

1. Wiggers, C. J. Cardiac Adaptations in Acute Progressive Anoxia. Ann. Int. Med. 14 (1). 1237-1247 (1941).

2. Courville, Cyril B. Contributions to the Study of 'Cerebral Anoxia: Some Observations on I'ts History, Its Mechanics and Nature, the Importance of Its Circulatory Components and Its Significance in Evaluation of Certain Chronic Diseases of the Brain of Infancy and Early Childhood. Los Angeles: San Lucas Press (1953).

3. Bernard, C. Leçons sur les anesthésiques et sur l'asphyxie. Paris: J. B. Baillière (1875).

4. Courville, Cyril. B. Untoward Effects of Nitrous Oxide Anesthesia, with Particular Reference to Residual Neurologic and Psychiatric Manifestations. Mountain View, Calif.: Pacific Press Publishing Association (1939).

5. Lowenberg, K., Waggoner, R., \& Zbinden, $T$. Destruction of the Cerebral Cortex following Nitrous Oxide-Oxygen Anesthesia. Ann. Surg. 104 (5) : 801-810 (1936).

6. Ford, F. R., Walsh, F. B., \& JARvis, J. A. Case of extensive injury to cerebral cortex following nitrous oxide-ether anaesthesia. Bull. Johns Hopkins Hosp. 61 (4) 246-257 (1937).

7. O'Brien, J. D., \& Steegman, A. T. Severe Degeneration of the Brain following Nitrous Oxide-Oxygen Anesthesia. Ann. Surg. 107 (4): 486-491 (1938).

8. Gebauer, P. W., \& Coleman, F. P. Postanesthetic Encephalopathy following Cyclopropane. Ann. Surg. 107 (4): 481-485 (1938).

9. Courville, Cyril B. Ether Anesthesia and Cerebral Anoxia: A Study of the Causative Factors in the Serious Anesthetic and Post-anesthetic Complications. Anesthesiology $2(1)$ : 44-58 (1941). 
10. Beecher, H. K., \& Tod, D. P. A Study of Death Associated with Anesthesia and Surgery Based on a Study of 599,548 Anesthesias in 10 Institutions, 1948-1952, Inclusive. Ann. Surg. 140 (1): 2-35 (1954).

11. Olsen, C. W.; Marinacci, A. A.; Ray, J. W.; \& Aimyes, E. W. Intravenous Procaine Hydrochloride in the Treatment of Asphyxia due to Carbon Monoxide: Report of Three Treated Cases and Two Untreated Cases with Electroencephalographic Correlation. Bull. Los Angeles Neurol. Soc. 14 (1): 23-31 (1949).

12. Courville, Cyril B. General Anesthesia and the Vulnerable Brain. J. Michigan Med. Soc. 59 (7): 1057-1061 (1960). 